\title{
Kawahiva: do Diagnóstico de Vulnerabilidade à Documentação
}

\author{
Kawahiva: from the Vulnerability Assessment to the Documentation
}

\section{Wesley Nascimento dos Santos}

University of California, Berkeley

Resumo. Este texto trata da documentação linguística da língua falada por vários povos amazônicos autodenominados Kawahiva. Mais especificamente, descreve-se o percurso pelo qual o Projeto de Documentação Linguística Kawahiva tem seguido, desde o censo sobre a vulnerabilidade da língua até o atual estágio, quando técnicas de salvaguarda da sua cultura verbal foram implementadas. A construção do quadro aqui relatado foi proporcionada por trabalhos de campo realizados no âmbito do Inventário Nacional de Diversidade Linguística (INDL) com os Kawahiva em 2017, e do projeto de documentação propriamente dito que computam um total de oito meses. Ao final, o leitor ganhará acesso ao reporte de uma parte importante do trabalho com os Kawahiva, qual seja, o diagnóstico de vulnerabilidade que permitiu a implementação do projeto voltado à salvaguarda da língua.

Palavras-chave: Línguas Ameaçadas; Documentação Linguística; Kawahiva.

\begin{abstract}
This paper reports on the language documentation of a language spoken by many Amazonian groups, autodesignated Kawahiva. More specifically, it describes the paths the Kawahiva Language Documentation Project has taken so far, beginning with a census of the vulnerability of Kawahiva, until the current step where strategies of safeguard have been applied. The broad picture reported here was made possible by field work that took place during the National Survey of Linguistic Diversity (INDL) with the Kawahiva in 2017, and well as the language documentation project proper, which together amounted to eight weeks of field works. In the end, the reader gains access to a report on an important part of the language documentation of Kawahiva, namely the vulnerability assessment that allowed the project dedicated to the safeguard of the language to be implemented.
\end{abstract}

Keywords: Endangered Languages; Language Documentation; Kawahiva.

\section{Introdução}

O final do último milênio se viu na urgência de documentar as línguas do mundo, principalmente aquelas com sério risco de desaparecimento, dado o seu rápido grau de extinção, impactadas por um crescente contexto de globalização (HALE, 1992). A isso, a Linguística respondeu com a criação de uma área especializada com o fim de documentar a cultura verbal das línguas do mundo, conhecida por Documentação Linguística. Resultante dessa estratégia, na última década, viu-se o florescimento de diversas medidas que colaboraram na solidificação dessa subárea, dentre as quais a criação de periódicos (ex.: LD\&C) ${ }^{1}$ e congressos (ex.: ICLDC) especializados na publicação de trabalhos resultantes da documentação de línguas específicas, para citar alguns.

No Brasil, os efeitos se fizeram ver pelo aumento no número de trabalhos de cunho descritivo, que passaram a contrastar com as décadas de análises no seio da Sintaxe Transformacionalista, em boa parte conduzidas por membros da missão Summer Institute of Linguistics (SIL) (ou Sociedade Internacional de Linguística). Muitas línguas brasileiras que

\footnotetext{
${ }^{1}$ http://nflrc.hawaii.edu/ldc/.
} 
receberam alguma análise transformacionalista elaboradas por missionários desse período, no entanto, não contam até hoje com uma descrição moderna da sua gramática, embora seu risco de desaparecimento seja elevado. Até o ano de 2017 esse era o contexto no qual virtualmente todos as variedades da língua Kawahiva se encontravam.

Este texto reporta os contornos que a documentação linguística do Kawahiva está tomando, especificamente desde um levantamento institucional, o Inventário Nacional de Diversidade Linguística (INDL), que permitiu a aferição do seu nível de vulnerabilidade até a implementação de estratégias de salvaguarda listadas como prioridade pelos povos falantes de Kawahiva, e implementadas por meio de um projeto de documentação linguística. Ao fim, espera-se contribuir com a literatura de documentação linguística de línguas indígenas brasileiras por meio do relato de aspectos de um projeto de documentação iniciado a partir de políticas públicas de estado que proporcionaram um melhor conhecimento da vulnerabilidade do Kawahiva e, no fim, ajudaram a delinear as melhores estratégias para a documentação dessa língua.

O texto está organizado da seguinte forma: na seção 2, há uma breve introdução a aspectos do povo (2.1) e língua Kawahiva (2.2). A seção 3 discute o diagnóstico de vulnerabilidade da língua e a situação sociolinguística desta em geral. A seção 4 descreve as estratégias de salvaguarda atualmente empregadas na documentação do Kawahiva.

\section{Kawahiva}

\subsection{Povo}

Os povos Kawahiva contatados somam um total de oito, localizados na bacia sudoeste amazônica, mais especificamente a do Rio Madeira. Esses povos são conhecidos pelos seguintes exônimos, com suas autodenominações, quando disponível, em parênteses: Amondawa, Capivari, Jiahui, Juma, Karipuna, Parintintin, Piripkura Tenharim (Pyri) e Uru-Eu-Wau-Wau (Jupau). Ainda há povos Kawahiva que vivem em isolamento na T.I Uru-Eu-Wau-Wau/RO ${ }^{2}$, T.I Tenharim Marmelos/AM e T.I Kawahiva do Rio Pardo/MT. Em quase todos os casos, a língua Kawahiva se encontra seriamente ameaçada de extinção, dado o seu baixo grau de transmissão à geração mais jovem - à exceção dos Tenharim da T.I Marmelos, onde a transmissão da língua se encontra estável.

A estrutura social dos Kawahiva se dá pela organização em metades exogâmicas, ou seja, membros de uma determinada metade devem obrigatoriamente se casar com membros que não pertencem a sua própria metade. As metades são tidas como localizadas usando-se o nome de aves. Por exemplo, os Uru-Eu-Wau-Wau se dividem entre as metades Kwandua 'gavião' e Mutum; Os Karipuna, entre os Mutum e Tarave 'curica'. As metades também são patriarcais, o que significa que a metade à qual um membro pertence é herdada do pai, e o sistema de matrimônio é patrilocal, o

\footnotetext{
${ }^{2}$ Os Uru-Eu-Wau-Wau chamam a esse povo de Jurure'i. Além deste, outro povo que vive na T.I Uru-Eu-Wau-Wau, mas não é reconhecido pelos Uru-Eu-Wau-Wau como Kawahiva, é chamado de Wyraparakwara (wyrapara 'flecha' + kwara 'buraco, sol'). Os relatos de alguns Uru-Eu-Wau-Wau que viveram antes do contato do povo, na década de 80, dão conta de que os Wyraparakwara possam ser um grupo Wari', falantes de língua Txapacura.
} 
que corresponde a uma configuração social em que o homem migra para a aldeia da mulher e passa a viver na casa dos pais da esposa após o casamento.

\subsection{Língua}

Os falantes de Kawahiva estão localizados no sudeste Amazônico, especificamente nas regiões de interflúvio dos afluentes do rio Madeira, nos estados de Rondônia (Uru-Eu-Wau-Wau, Amondawa, Capivari e Karipuna), Amazonas (Parintintin, Tenharim, Juma e Jiahui) e Mato Grosso (Piripkura). A língua Kawahiva pertence à família Tupi-Guarani (TG), que junto das famílias Arikém, Juruna, Mondé, Mundurukú, Ramarama-Puroborá, Tupari, Mawé e Awetí compõem o tronco linguístico Tupi (RODRIGUES; CABRAL, 2002; MICHAEL et al., 2015). Trata-se da única língua representante da família Tupi-Guarani em Rondônia, considerado o mais diverso linguisticamente no país (GALUCIO et al., 2018).

As diferenças internas entre os dialetos Kawahiva foram foco de um estudo comparativo do léxico e da fonologia realizado por Sampaio (1997), que demonstrou ser a língua falada pelos Parintintin, Tenharim, Uru-Eu-Wau-Wau e Amondawa variedades de uma mesma língua, com relações internas mais próximas entre Parintintin e Tenharim, de um lado, e Uru-Eu-Wau-Wau e Amondawa, de outro.

Tipologicamente, Kawahiva é uma língua cuja ordem de palavras exibe a configuração complemento-núcleo, e a ordem de constituintes discursivamente neutra é a VSO. O sistema de alinhamento dos argumentos da oração segue o padrão nominativo, manifestado pelo mesmo paradigma de prefixos verbais usados para indexar o único argumento de predicados intransitivos ergativos e o argumento externo de predicados transitivos. Cisões nesse padrão são observadas: apenas em Karipuna, quando a oração envolve participantes locais (primeira ou segunda pessoa), em que uma primeira pessoa singular ou exclusiva age sobre uma segunda pessoa singular e plural, os prefixos portmanteaux oro- e opo- são utilizados, respectivamente. Ademais, uma hierarquia de pessoa do tipo 1>2>3 condiciona o padrão absolutivo, quando participantes mais altos nessa hierarquia são tratados como argumentos internos de verbos cujos argumentos externos são mais baixos na hierarquia (i.e. $3>1,2 ; 2>1$ ). Neste caso, os clíticos que marcam o argumento único de predicados intransitivos inacusativos são utilizados para marcar o argumento interno nessas configurações. A concordância verbal é cancelada sempre que qualquer sintagma não argumental é deslocado para uma posição estrutural acima daquela do sintagma verbal, caso em que o verbo também apresenta morfologia especial por meio do sufixo -i.

Semanticamente, nomes podem ou não ser nus. Enclíticos que marcam definitude são obrigatórios em textos e flexionam o nome em gênero e número. Quando nus, os nomes não distinguem número e não apresentam o contraste definido vs. indefinido. A distinção semântica básica de tempo é a de passado vs. não-passado. O não-passado é marcado por partículas com posição fixa, seja segunda posição, ou final de sentença, enquanto o primeiro é não-marcado. Ou seja, orações não marcadas para tempo sempre terão sua semântica temporal igual ou anterior ao tempo do enunciado. Somam-se às marcas de tempo já mencionadas um conjunto de partículas que codifica evidencialidade e outras distinções aspectuais (ex.: perfectivo). 


\section{Diagnóstico de vulnerabilidade}

Para a discussão sobre o levantamento da vulnerabilidade da língua Kawahiva são necessárias algumas palavras para contextualizar os motivos que levaram a um projeto de levantamento da língua em primeiro lugar para, então, seguirmos com o levantamento propriamente dito.

\subsection{Inventário Nacional de Diversidade Linguística}

Foi graças ao Inventário Nacional de Diversidade Linguística (INDL) que o estado de vulnerabilidade do Kawahiva pode ser aferido ou, mais especificamente, a situação das variedades faladas no estado Rondônia. O INDL foi estabelecido por meio de um decreto federal, n. 7.387, de 9 de dezembro de 2010 (REPÚBLICA FEDERATIVA DO BRASIL, 2010), e é uma política pública resultado da mobilização de órgãos da sociedade civil e governamentais "para o reconhecimento da diversidade linguística como patrimônio cultural, por meio da identificação, documentação e ações de apoio e fomento" 3 (website IPHAN, 2019). Os objetivos do projeto eram justamente (i) "promover e valorizar a diversidade linguística brasileira", (ii) "fomentar a produção de conhecimento e documentação sobre as línguas faladas no Brasil" e (iii) "contribuir para a garantia de direitos linguísticos" (website IPHAN, 2019). Da forma como está desenhado, a proposta do inventário em si e sua execução são resultados da busca da concretização de (i), enquanto (ii) e (iii) seriam alcançados, respectivamente, na medida em que as línguas inventariadas passassem a ser conhecidas por meio do material documental coletado e reconhecidas como patrimônio cultural do país, bem como garantias para sua manutenção fossem executadas.

A fim de fomentar a produção de conhecimento sobre a diversidade linguística brasileira, o Instituto de Patrimônio Histórico Artístico Nacional (IPHAN) abriu uma seleção para submissão de propostas a fim de apoiar projetos-piloto de documentação. Dentre os projetos aprovados, estava o de Documentação da Situação Sociolinguística de Rondônia, proposto pela área de Linguística do Museu Paraense Emílio Goeldi (MPEG). Uma discussão detalhada sobre o projeto, metodologia e seus resultados em larga escala podem ser encontrados em Galucio et al. (2018). Dentre os resultados mais importantes a serem salientados desse trabalho está o fato de que Rondônia é o estado mais diverso linguisticamente do país, com o total de 26 línguas e uma população indígena de 11.218 pessoas (Galucio 2018, p. 212).

\subsection{O INDL e os Kawahiva}

As variedades Kawahiva incluídas no INDL foram aquelas faladas em Rondônia: Amondawa, Capivari, Karipuna e Uru-Eu-Wau-Wau. Dada a situação de virtual extinção do Capivari, para a qual somente um falante tem sido identificado até o presente momento, os trabalhos de campo para coleta de material documental se concentraram nos demais dialetos. No que segue, dados sobre as demais variedades também são considerados quando possível. Os dados específicos da situação do Kawahiva e outras questões importantes que o levantamento se propôs a conhecer são apresentados e discutidos nas próximas seções.

\footnotetext{
${ }^{3}$ http://portal.iphan.gov.br/pagina/detalhes/140.
} 


\subsubsection{Localização, população, falantes e esferas de uso da língua}

Os Amondawa e Uru-Eu-Wau-Wau vivem na Terra Indígena Uru-Eu-Wau-Wau, organizados em seis aldeias, enquanto os Amondawa estão concentrados em uma única aldeia, a Trincheira. Os Karipuna estão na T.I Karipuna, numa única aldeia, a Panorama. O único falante de Capivari vive com os Karitiana. Os Tenharim vivem nas T.Is Tenharim Marmelos, Tenharim Marmelos (Gleba B) e Tenharim Igarapé Preto, e têm12 aldeias segundo relatam. Os Parintintin vivem na T.I Nove de Janeiro e, ao norte desta, na T.I Ipixuna, e têm três aldeias. Os Jiahui também moram na T.I Jiahui, e contam com três aldeias. Outro povo Kawahiva no Amazonas é o Juma, que vive na T.I Juma, numa única aldeia. No Mato Grosso vivem os Piripkura, com dois dos seus membros em isolamento, enquanto outro é casado com um Karipuna.

É sentimento geral entre os Kawahiva que a língua e cultura estão sendo perdidas. Conforme o relato dos próprios indígenas, isso se deve a vários fatores, como o contato com não-indígenas e, mais especificamente, a saída precoce dos mais jovens para estudar na escola não-indígena por falta de oferta das modalidades de ensino pós-primeira fase do Ensino Fundamental (i.e., segunda fase e o Ensino Médio).

Considerando a variável população e número de falante por estado, os números disponíveis no quadro 1 abaixo apontam para mais de $40 \%$ de não-falantes em Rondônia. Esse quadro sumariza o número de pessoas e falantes em Rondônia, dados levantados in loco, durante o INDL.

Quadro 1. População e falantes de Kawahiva em Rondônia.

\begin{tabular}{|c|c|c|}
\hline Povo & População & Falantes \\
\hline Amondawa & 126 & 10 \\
\hline Karipuna & 29 & 64 \\
\hline Uru-Eu-Wau-Wau & 108 & 1 \\
\hline Capivari & 1 & 10 \\
\hline
\end{tabular}

É preocupante a situação dos Uru-Eu-Wau-Wau, por exemplo, que contatados no início da década de 80 (assim como os Amondawa), com raras exceções, veem seus jovens se tornarem bilíngues passivos. O caso mais delicado entre os Kawahiva de Rondônia é o dos Karipuna, com 29 indivíduos e 10 falantes. Destes, apenas cinco vivem na aldeia.

No quadro 2, a seguir, as variáveis fluente, proficiente parcial (ou bilíngue passivo) e nãofalante são utilizadas para computar o número absoluto de cada uma, o que permite aferir se a transmissão da língua está em andamento ou estacionada em algum ponto entre as gerações. Os dados do quadro 2 dizem respeito aos Kawahiva de Rondônia apenas.

Embora, em números absolutos, o número de falantes fluentes supere a soma dos proficientes parciais mais não-falantes, 59,54\% contra 40,46\%, é a variável Infância e Juventude (abreviados em Inf./Juv), que corresponde a indígenas de 0 a 25 anos, que deve ser considerada para fins de categorização do status de vitalidade da língua, já que se trata da faixa etária para a qual a língua é, em um cenário normal, transmitida e assim continua a ser falada. Neste sentido, a soma do número de proficientes parciais mais não-falantes $65,22 \%$ supera o de falantes fluentes, $37,78 \%$. 
Quadro 2. Falantes de Kawahiva por faixa etária em Rondônia.

\begin{tabular}{|c|c|c|c|}
\hline & Fluente & Proficiente Parcial & Não-Falante \\
\hline Inf./Juv.: 0-25 & $56(34,78 \%)$ & $27(16,77 \%)$ & $78(48,45 \%)$ \\
\hline Adulta I: $\mathbf{2 6 - 4 0}$ & $44(97,78 \%)$ & 0 & $1(2,22 \%)$ \\
\hline Adulta II: 41-59 & $40(100 \%)$ & 0 & 0 \\
\hline Idoso: $+\mathbf{6 0}$ & $16(100 \%)$ & 0 & 0 \\
\hline Total & $156(59,54 \%)$ & $27(10,31 \%)$ & $79(30,15 \%)$ \\
\hline
\end{tabular}

O quadro 3 se baseia nos dados de Moore et al. (2008) para estimar o número de indivíduos e falantes Kawahiva no Amazonas. Pouco se sabe sobre o estágio de perda da língua por faixa etária dos Parintintin, Tenharim e Jiahui. Os dados sobre os Juma proveem de recente trabalho de campo na T.I Juma, quando se pode levantar, in loco, os números aqui apresentados.

Quadro 3. População e falantes de Kawahiva no Amazonas.

\begin{tabular}{|c|c|c|c|}
\hline Povo & População & Falantes & Povo \\
\hline Parintintin & 156 & 10 & Parintintin \\
\hline Tenharim & 585 & 350 & Tenharim \\
\hline Jiahui & 50 & 1 & Jiahui \\
\hline Juma & 4 & 4 & Juma \\
\hline Total & 795 & 365 & Total \\
\hline
\end{tabular}

Quanto às esferas de uso da língua, ou seja, o uso do Kawahiva como meio de comunicação oral no cotidiano, como língua de instrução ou língua cerimonial, alguns pontos merecem destaque.

Em Rondônia, o Kawahiva ainda é usado como meio de comunicação entre pessoas com idade superior a 25 anos e predomina como a língua de festas tradicionais. Pessoas com idade inferior a 25 usam o Português. Entre os Karipuna, pela sua condição de interrupção, o Kawahiva se restringe aos mais velhos. Kawahiva é a língua de instrução somente entre os Amondawa e Uru-EuWau-Wau, quando é utilizado nas aulas de língua materna. No Amazonas, com exceção dos Juma, as únicas informações de que se dispõem sobre a condição de uso das demais variedades foram obtidas por meio de relatos com indígenas que visitam as aldeias dos Kawahiva em Rondônia, mensagens com lideranças por meio de aplicativos de mensagens ou encontros casuais em cidades circunvizinhas às aldeias. Estes dão conta de que, ao menos na T.I Marmelos, os Tenharim têm o Kawahiva como língua de comunicação em todas as esferas da vida social. Os Parintintin usam o Kawahiva em festas tradicionais, tais como cerimônias, mas seu uso no cotidiano da aldeia predomina somente entre os mais velhos. Quanto aos Jiahui, conforme a liderança desse povo, o Kawahiva é ouvido somente entre os mais velhos, e não é a língua de instrução na escola. No caso dos Juma, a língua é o principal meio de comunicação na comunidade, que também conta com indígenas Uru-Eu-Wau-Wau, e o Português é utilizado somente pelos mais jovens, que são bilíngues passivos. 


\subsubsection{Nível de documentação linguística do Kawahiva}

A documentação do Kawahiva é escassa, e pode se dizer que o conhecimento de que se dispõe até o momento dos dialetos Amondawa, Jiahui, Juma, Karipuna, Piripkura e Tenharim é praticamente inexistente. Ademais, o foco dos trabalhos anteriores tem sido sua fonologia, e até o presente momento não há uma gramática descritiva da língua. A descrição das referências a seguir não pretende ser exaustiva, mas lista as principais contribuições à literatura Kawahiva de que se pode ter acesso até o presente momento.

A fonologia do Parintintin (PEASE; BETTS, 1971) tem somente 14 páginas; o esboço da gramática (PEASE, 2007 [1968]), um mistura de Tagmêmica e Sintaxe Transformacional, com 78 páginas, não foi atualizada desde 1968; e uma descrição da expressão de tópico, baseada em três textos (BETTS, 2008 [1968]), também não é atualizada desde então. Os maiores trabalhos são o dicionário de Parintintin (BETTS, 1981) e o dicionário Kagwahiva (BETTS, 2012). Este dicionário tem por base pesquisas de longa duração entre os Parintintin e os Tenharim, e pesquisas de aproximadamente duas semanas cada entre os Amondawa, Karipuna e Uru-Eu-Wau-Wau. Estudos menos expressivos são Betts (2008 [1969]; 1971) e Pease (1979/80). O Tenharim ainda apresenta uma análise fonêmica preliminar de alguns segmentos (ex.: fricativas) e da nasalização (BORELLA, 1996, 1997, 1998, 1999). O dialeto Juma tem uma análise inicial da fonologia segmental da língua em Abrahamson (1968) e Abrahamson e Abrahamson (1984), este sendo uma tradução para o Português do primeiro, e se trata de um manuscrito ainda não digitalizado e provavelmente perdido no incêndio que atingiu o Museu Nacional/RJ no ano de 2018.

Entre os trabalhos com as variedades Uru-Eu-Wau-Wau e Amondawa, há um estudo de natureza preliminar de Pease e Betts (1991) (provavelmente também perdido no incêndio mencionado acima), uma breve análise fonêmica para o Amondawa de Netto e Oliveira (1993) e uma recente comparação entre Amondawa, Jiahui e Tenharim em Marçoli (2018). Além da comparação de variedades e classificação interna dos dialetos Kawahiva de Sampaio (respectivamente 1997, 2001), a autora trabalhou com os psicolinguistas Chris Sinha e Vera da Silva em pesquisas que combinam Linguística, Psicologia e Antropologia (SAMPAIO; SINHA; DA SILVA, 2004, 2009; SINHA, DA SILVA; ZINKEN; SAMPAIO, 2011). Sampaio, da Silva e Miorello (2004) contribuíram com uma coleção de mitos Amondawa com versão monolíngue em Português. Do Piripkura não há material publicado. Uma tese histórico-comparativo (Aguilar 2015) trata da diversificação do subramo VI da família Tupi-Guarani, no qual as variedades Kawahiva são agrupadas por Rodrigues e Cabral (2002).

\subsubsection{Escrita}

Praticamente todos os dialetos Kawahiva (com exceção do Capivari e Piripkura, pela situação singular de virtual extinção desses povos já antes do contato) tiveram propostas de grafia. No caso dos Kawahiva de Rondônia, os Amondawa atribuem a uma linguista da Universidade Federal de Rondônia a grafia que utilizam. Os Uru-Eu-Wau-Wau das aldeias Jaikara, 623 e Aldeia Nova contam que um homem de nacionalidade alemã, sem treinamento linguístico, foi o responsável pela sua grafia. Os Uru-Eu-Wau-Wau mais ao norte da reserva indígena, Jamari e Alto Jamari, mencionam 
que missionários da JOCUM (Jovens com Uma Missão), após um período de aprendizado da língua, elaboraram uma grafia que passou a ser ensinada na escola da aldeia durante a alfabetização dos indígenas. Os Karipuna, por sua vez, creditam a funcionários da Secretaria de Educação a grafia que conhecem. Em todos os casos, o uso da grafia se restringe ao ambiente escolar.

Pouca informação há a respeito da utilização da grafia pelos povos Kawahiva do Amazonas, com exceção dos Juma. Neste caso, observou-se que a grafia também se restringe ao contexto da escola. A professora Juma adquiriu a grafia durante o período em que todos os Juma moravam na T.I Uru-Eu-Wau-Wau, em decorrência de casamentos interétnicos entre esses povos. Relatos de uma liderança Jiahui dão conta de que algumas pessoas sabem escrever na língua, mas que seu uso se restringe à sala de aula, cenário igual ao qual se teve conhecimento por parte dos Tenharim e Parintintin, durante o I Encontro Kawahiva ${ }^{4}$, quando também relataram suas dificuldades com o ensino da escrita da língua, ao que culpavam a arbitrariedade no emprego de alguns grafemas.

\subsubsection{Prioridades para a salvaguarda da língua}

Como parte das estratégias para salvaguarda da língua, o INDL incluiu uma lista de itens com estratégias para salvaguarda de línguas vulneráveis, a serem ranqueados pelos povos recenseados conforme o nível de prioridade que o povo atribuiria a essas estratégias. Os 15 itens constantes na lista e apresentados aos povos foram ranqueados numa escala com as variáveis alto, médio e baixo.

1. Assessoria para resolver problemas de ortografia;

2. Assessoria para montar um programa de revitalização da língua;

3. Documentação digital da língua e cultura verbal por meio de gravações de áudio e de vídeo, com copias para o uso da comunidade;

4. Treinamento em documentação digital;

5. Aquisição de equipamentos para gravação e edição de áudio e vídeo (somente onde já existe treinamento suficiente);

6. Documentação escrita da língua, dicionários, coletâneas de histórias, etc;

7. Correção de materiais didáticas existentes e aumento da sua quantidade;

8. Confecção de mais materiais didáticos na língua;

9. Uso da língua como meio de instrução (na medida possível);

10. Ensino da língua como disciplina na escola (se não já existe);

11. Ensino de conhecimentos tradicionais na escola;

12. Apoio para festas e outras práticas tradicionais que usam a língua;

13. Reconhecimento de língua como referência cultural;

14. Oficialização da língua;

15. Proteção contra pessoas ou organizações que se oponham a cultura verbal tradicional (por exemplo, festas tradicionais, pajelança).

\footnotetext{
${ }^{4}$ Realizado nos dias 1-3 de Junho de 2018, na aldeia Marmelos, do povo Tenharim.
} 
É interessante observar que as prioridades mais altas desta lista podem delinear um projeto de documentação que tem grandes chances de ser bem-sucedido, porque considera a participação do povo na sua elaboração. Foi exatamente isso que aconteceu durante a proposta de documentação da língua dos Kawahiva de Rondônia, que considerou os itens ranqueados como mais prioritários. Por unanimidade, as estratégias escolhidas foram (1) assessoria para resolver problemas de ortografia, (3) a documentação digital da língua e cultura verbal por meio de gravações de áudio e de vídeo, com cópias para o uso da comunidade e (4) o treinamento em documentação digital, carros-chefe do projeto que documenta sua língua, do qual se passa a tratar na próxima seção.

\section{Documentação Linguística Kawahiva}

A documentação do Kawahiva é uma prioridade para a documentação linguística dado o nível bem reduzido de falantes da língua e o seu contato recente com a sociedade nacional, o que pode levar ao desaparecimento da língua em poucas gerações. Assim, contribuir com a escassa literatura linguística sobre o Kawahiva é uma tarefa urgente. A documentação linguística de línguas em alto risco de desaparecimento, como o Kawahiva, é considerada uma tarefa fundamental e crucial pelos linguistas em função do alto nível de desaparecimento de diversidade linguística pela qual o mundo passa (NETTLE; ROMAINE 2000).

Os objetivos da documentação da língua Kawahiva se enquadram perfeitamente no campo da Documentação Linguística (HIMMELMAN, 1998), uma subdisciplina da linguística que emergiu nos últimos 15 a 20 anos em resposta ao crescimento da vulnerabilidade e extinção da diversidade linguística.

A documentação linguística objetiva criar materiais que sirvam como documentação dos recursos lexicais e gramaticais de uma dada língua, incluindo documentação em áudio e representação textual da língua, listas de palavras, sentenças elicitadas e transcrição e tradução de narrativas orais. Projetos de documentação linguística se concentram primariamente na criação desses recursos, com a intenção de torná-los disponíveis para outros linguistas para análises futuras da língua. O projeto de documentação linguística Kawahiva objetiva desenvolver uma documentação de igual natureza à descrita acima com uma língua que está à beira da extinção.

Neste sentido, como já apontado, o projeto de documentação da língua dos Kawahiva é fruto da demanda dos próprios indígenas, que manifestaram interesse em participar e ter sua língua documentada após o levantamento do INDL, durante o qual elegeram prioridades para a salvaguarda da língua. Manifestações de interesse em documentação também foram recebidas no I Encontro Kawahiva por parte dos Kawahiva do Amazonas. Na oportunidade, estavam presentes representantes dos povos Tenharim, Parintintin, Jiahui, Uru-Eu-Wau-Wau e Karipuna, que se interessam pela possibilidade de extensão do projeto de documentação para os seus povos. 0 coordenador do projeto teve a oportunidade de compartilhar os resultados do INDL, em que tratou dos níveis de vitalidade dos dialetos de Rondônia e a documentação em andamento com os Uru-EuWau-Wau e Karipuna. A seção de discussão das falas apresentadas, que contou com a contribuição de antropólogos e representantes de outras instituições, permitiu que vários indígenas tecessem comentários sobre a situação da língua falada por seu povo. Em geral, os indígenas apontavam para 
a não-transmissão da língua aos jovens, falta de assistência com problemas relacionados à escrita e indisponibilidade de materiais didáticos para auxiliar o professor indígena em sala de aula. Ao final das considerações, cada povo presente manifestou interesse em participar do projeto de documentação, assinando um termo de compromisso que também reconhecia a vulnerabilidade das suas línguas.

As próximas seções abordam alguns aspectos do projeto de documentação com os Kawahiva, que vão desde as primeiras interações com os povos à implementação de estratégias de documentação para salvaguarda da língua.

\subsection{Primeiros momentos}

As atividades do projeto são realizadas nas terras indígenas dos povos participantes. Como já mencionado, os Kawahiva manifestaram interesse e entusiasmo ao Projeto de Documentação Linguística Kawahiva, haja vista que o projeto se encaixa perfeitamente nos seus planos para documentar sua língua.

Em uma primeira visita à aldeia dos povos participantes, uma reunião para discutir aspectos da documentação, tais como objetivos, metodologia e resultados esperados é realizada com os membros das aldeias. Potenciais consultores são informalmente convidados a participarem do projeto, momento durante o qual também são tratadas a natureza das tarefas nas quais eles se engajarão e a compensação que lhes será devida. Os falantes são convidados a se manifestarem e discutirem eventuais dúvidas que Ihes ocorrerem. Após esse momento, consentimento verbal e escrito é obtido do pesquisador-indígena pelo linguista.

Dado que o linguista se instala na aldeia, os membros que aceitam participar mais diretamente como consultores ou demais membros do povo podem visitar o linguista para, por exemplo, discutir aspectos do projeto que porventura não tenham ficado tão claros durante a reunião.

\subsection{Metodologia}

O projeto de documentação linguística Kawahiva tem empregado as metodologias tradicionais da descrição e documentação linguística, seguindo as melhores práticas atualmente utilizadas no que se refere à ética (Linguistic Society of America Ethics Statement:http://Isaethics.wordpress.com/), coleta de dados (Digital Resource Creation:http://emeld.org/school/toolroom/software/index.cfm), preservação de material (BIRD; SIMONS, 2003) e descrição e análise linguística (DIXON, 1998; DRYER, 2006).

As três metodologias-chaves utilizadas no projeto são elicitação lexical, sintática e transcrição e tradução de textos orais. Todas as sessões de elicitação são registradas em áudio, e a depender da natureza do estímulo utilizado (figuras etc.), também em vídeo, considerando a permissão do consultor para tal.

Essas três metodologias têm sido empregadas simultaneamente durante o curso das visitas a campo. Todo o material de áudio, vídeo e texto (notas de campo) tem sido duplicado e arquivado no repositório do Museu do Índio e na Survey for California and Other Indian Languages (http://linguistics.berkeley.edu/Survey/), na coleção Kawahiva Language Documentation Archive, 
hospedado na Instituição do coordenador. O arquivamento digital permanente de recursos de documentação linguística é peça-chave nas boas práticas que regem a documentação linguística (BIRD; SIMONS, 2003)

\subsection{Frutos do projeto}

Os objetivos do projeto são apresentados aos povos participantes na primeira reunião, durante a qual os prazos e produtos esperados são discutidos. No momento em que se redigia este texto, todos os grupos envolvidos e o linguista têm uma agenda cujos objetivos visam a elaboração de materiais para documentação e salvaguarda da língua. Parte do material pensado tem por base a trilogia boasiana, dicionário-coletânea de textos-gramática.

\subsubsection{Dicionário Multimídia}

O Projeto de Documentação de Línguas Indígenas (Prodoclin), fruto de uma parceria entre Museu do Índio/FUNAl e Unesco, tem apoiado projetos colaborativos de documentação de línguas indígenas faladas no território nacional por povos de recém-contato desde 2009 por meio de editais publicados na página de ambas instituições. Trata-se de uma das políticas de documentação mais abrangentes em vigência no território nacional de que se dispõem notícias.

Em 2019, o edital lançado pela Unesco, como acontece em cada etapa do Prodoclin, tinha como objetivo comum para todas as propostas submetidas um dicionário digital para as línguas previamente selecionadas no edital. O edital, portanto, solicitava que pesquisadores, linguistas ou antropólogos, que contavam com experiência prévia de dois anos de trabalho com as línguas selecionadas (seja em campo ou gabinete), submetessem suas propostas considerando como produto final do trabalho um dicionário multimídia. Os projetos apoiados pelo edital em questão deveriam prever envolvimento direto de membros dos povos envolvidos no processo de elaboração, caso em que dois indígenas são convidados a participarem como pesquisadores-indígenas.

No contexto dos Kawahiva, a primeira versão do dicionário multimídia Kawahiva-Português em desenvolvimento conterá o mínimo de 800 itens lexicais, incluindo transcrição fonética, grafia em Kawahiva, tradução em Português, ocorrências (provenientes de textos de fala espontânea ou de oficinais criadas para esse propósito) do uso da palavra e um token de áudio do item. Os itens lexicais que comporão o dicionário fazem parte de uma lista de palavras dividida pelos seguintes campos: números, partes do corpo, alimento, animais, termos de parentesco, cores, plantas, itens da cultura material, adjetivais, adverbiais e verbos. A ordem de apresentação dos itens seguirá uma ordem alfabética. Ademais, dado que nomes inalienáveis, na sua forma de citação, sempre são acompanhados de prefixos que codificam o possuidor, e raízes verbais na sua forma finita contam com prefixos de concordância, os indígenas decidiram pela utilizam da base (e não da raíz) como referência para a inserção do item lexical em questão no dicionário. 


\subsubsection{Coletânea bilíngue de textos}

A demanda por uma coletânea de textos tradicionais ou de autoria indígena sempre esteve presente nos diálogos sobre a documentação da língua. Os indígenas lamentam a falta de material na língua, e sentem a necessidade de um material literário na própria língua, que também ecoe as suas vozes por meio dos textos orais de autoria individual, ou as narrativas tradicionais que sempre escutaram quando crianças, mas à qual a geração mais jovem não está tendo a oportunidade de acesso pela pouca inclusão da cultura verbal do povo na sala de aula. É frequente a comparação entre o quantitativo de livros literários em Português que chegam nas escolas indígenas e a inexistência de ao menos um que retrate os mitos do povo, suas danças, flautas, costumes, restrições alimentares etc., a partir do qual, provavelmente, as crianças teriam mais interesse pela cultura indígena e a partir disso o interesse pelo aprendizado da língua dos pais aumentaria.

Por conta disso, uma coletânea bilíngue de textos previamente selecionados pelos indígenas está sendo elaborada para uso em sala de aula e distribuição entre os povos participantes ou não do projeto. Uma amostra da coletânea pode ser encontrada aqui.

\subsubsection{Gramática Descritiva}

No Brasil, ainda há uma tradição relativamente incipiente de descrições linguísticas completas, como teses doutorais ou monografias, independentes resultados de documentação. Algumas descrições completas foram realizadas, geralmente, por linguistas que estudaram no exterior, como por exemplo a descrição do Kamaiurá por Seki (2000).

Trabalhos de documentação que empreguem métodos de descrição linguística moderna podem contribuir com análises inovadoras que têm sido oferecidas à família Tupi-Guarani, bem como línguas Tupi em geral. Por exemplo, Meira e Drude (2013) defendem que os "prefixos relacionais" postulados para línguas Tupi-Guarani podem ser diacronicamente reconstruídos e não podem ser usados como evidências para relações com outras famílias ou troncos linguísticos. Os autores, no entanto, apontam para a escassez de dados de paradigmas nominais que vários trabalhos com línguas Tupi-Guarani não apresentam, a exemplo do paradigma de prefixos reflexivos de nomes inalienáveis ("ele cortou o próprio pé"). Michael et. al (2015) usaram métodos filogenéticos para determinar a classificação interna do Tupi-Guarani, o que difere em alguns pontos daquela mais comumente difundida nos estudos dessa família. A base de dados dos autores, no entanto, não inclui línguas como o Apiaká - considerada uma das mais próximas do Kawahiva - pela indisponibilidade de dados lexicais suficientes para uma análise filogenética dessa língua, também seriamente ameaçada de extinção.

Uma contribuição importante no horizonte do projeto de documentação Kawahiva, portanto, além do dicionário multimídia e da coletânea de textos com cópias para usufruto das comunidades, será, a longo prazo, a elaboração de uma descrição da fonologia e gramática da língua. Dentre os tópicos interessantes da fonologia está, sem dúvida, a harmonia nasal, que é um dos principais traços tipológicos da família Tupi. Quanto à gramática, a literatura de línguas TupiGuarani ainda carece de uma análise sobre a assimetria no deslocamento de constituintes argumentais versus não-argumentais à periferia esquerda da oração. Argumentos deslocados para 
foco ou tópico não exibem a perda da concordância e morfologia verbal especial observados no deslocamento de adjuntos.

\subsubsection{Oficinas}

Oficinais para discussão do alfabeto e ortografia Kawahiva têm sido realizadas na aldeia de cada povo participante e estão previstas para se tornarem um evento permanente na agenda das suas associações, bem como das secretarias de educação responsáveis pelas escolas indígenas. Como em vários outros casos de documentação de línguas reportados ao redor do mundo, oficinas dessa natureza são benéficas não só para os povos, mas também para o linguista. É comum que estas levem à observação de aspectos da fonologia e gramática que o linguista porventura não tenha notado, ou mesmo à revisão de aspectos da descrição/análise que outrora se mostravam sólidos. $\mathrm{A}$ exemplo, na I Oficina da Língua Kawahiva dos Uru-Eu-Wau-Wau, realizada em julho de 2019, os participantes Uru-Eu-Wau-Wau chamaram a atenção do linguista para uma distribuição complementar não notada anteriormente.

Antes, uma breve descrição da distinção nome-verbo nessa língua. Em Kawahiva, como em várias outras línguas da família Tupi-Guarani, raízes lexicais só podem usadas como argumento quando sufixadas com o enclítico $a$. Sem o enclítico nominal, o item é um predicado, geralmente com a leitura de um existencial. Este, por exemplo, pode ser negado com o sufixo descontínuo de negação de predicados, [d...i] [n...i]. Veja-se o-nũpã [3-bater], que negado é $d$-o-nũpã-i [NEG-3-bater-NEG].

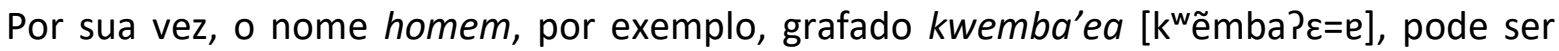
negado com [d...i] [n...i] de igual modo. Neste caso, no entanto, o enclítico não reaparece e a leitura que sem tem é o de negação de um predicado existencial: $d a-k w e m b a$ 'e-i 'não tem homem'. Com o enclítico, a negação procede com o sufixo $\{$-rõi\}, restrito a nomes e verbos nominalizados: kwemba'earõi 'não é homem'.

A relação paradigmática na qual o enclítico nominal se encontra e que foi observada pelos participantes da oficina surgiu quando estes observaram na grafia do linguista para a palavra homem a forma kwemba'ea ga. Os indígenas chamaram a atenção do linguista para a agramaticalidade na coocorrência do a entre a raiz kwemba'e e o enclítico ga. Depois de uma longa discussão, com o uso de outros exemplos e uma maior investigação da questão nos dias que se seguiram, concluiu-se que: em Kawahiva, $a$ não co-ocorre com outros enclíticos que se anexam a raízes nominais e que contribuem com um traço de definitude ${ }^{5}$ a essas raízes. Exemplo disso é [ $k^{\mathrm{w}}$ ẽmba? $\varepsilon=e$ ] 'homem' e [ $\mathrm{k}^{\mathrm{w} e ̃ m b a} \varepsilon=g a$ ] 'o homem', mas não *[ $k^{\mathrm{w}}$ ẽmba? $\varepsilon=\mathrm{a}=\mathrm{ga}$ ]. Além de $g a$, também anexam a raízes nominais [hẽa] 'terceira pessoa singular feminino' e [nã] 'terceira pessoa plural', este sem distinção de gênero. Viuse também que, além de nomes com traço humano, eles também podem ocorrer com nomes de animais, embora alguns falantes rejeitem essa possibilidade completamente. Em textos, nomes são obrigatoriamente subcategorizados com [ga], [hẽa] ou [nã].

\footnotetext{
${ }^{5}$ Ainda é cedo para dizer se o ingrediente a mais adicionado por esses enclíticos é, de fato, definitude, já que mesmo os nomes próprios podem recebê-los. Uma alternativa seria flexão de número no caso de todos estes enclíticos mencionados (singular e plural), e de gênero, restrito à terceira pessoa do singular. Seja qual for, esses enclíticos são inovações em Kawahiva, já que nomes em línguas Tupi-Guarani são nus, bem como nas famílias do mesmo tronco linguístico (ex.: Karitiana, família Arikém).
} 


\subsubsection{Participação da comunidade e capacitação de indígenas}

Projetos colaborativos, como o de documentação do Kawahiva, envolvem membros da comunidade indispensavelmente; afinal, sua natureza colaborativa decorre dessa configuração específica que envolve a participação direta dos indígenas no processo. Além disso, a agenda dos Kawahiva e linguista (ou antropólogo etc.) precisa estar equilibrada, no sentido de haver um balanço entre as expectativas de cada um dos envolvidos. Isso ajuda a evitar, por exemplo, que algumas expectativas do povo não sejam preenchidas e a figura do linguista se torne persona non grata. Os pesquisadoresindígenas selecionados como bolsistas do projeto com suporte do Museu do Índio/Funai e Unesco receberam treinamento por meio de oficinas nas quais são apresentadas a metodologia do projeto, as responsabilidades de cada pesquisador, o cronograma da pesquisa e os resultados esperados. Durante a oficina também são apresentadas e trabalhadas as ferramentas a serem utilizadas na documentação, como gravador, microfone, programa de transcrição e tradução de gravações em áudio e vídeo (ex.: ELAN) e programa de construção de léxico e interlinearização de textos (ex.: FLEX).

\section{Conclusão}

Neste texto, reportou-se uma parte significante da experiência que o projeto de documentação linguística do Kawahiva tem proporcionado aos indígenas e linguista coordenador do projeto. No fim, espera-se contribuir com a literatura de documentação linguística de línguas indígenas brasileiras pela descrição de aspectos de um projeto desde as políticas que proporcionaram que a situação de vulnerabilidade da língua fosse conhecida com acuidade à implementação da documentação colaborativa, que equilibra as expectativas do linguista quanto às suas obrigações com publicações etc., e a dos indígenas, com a salvaguarda da língua.

\section{Referências}

AGUILAR, A. M. G. C. Contribuições para os estudos histórico comparativos sobre a diversificação do subramo VI da família linguística Tupí-Guaraní. Tese (Doutorado em Linguística) - Universidade de Brasília. Brasília, 2015.

ABRAHAMSON, A.; ABRAHAMSON, J. Os Fonemas da Língua Júma. Série Linguística, n. 11, p. 157-174. 1984.

BETTS, L. V. D. Dicionário Parintintin-Português/Português-Parintintin. Cuiabá/MT: SIL, 1981. 231 p.

BETTS, L. V. D. Kagwahiva dictionary. Anápolis/GO: SIL, 2012. 295 p.

BETTS, L. V. D. Parintintin discourse. Anápolis/GO: SIL, 2008 [1969]. 79p.

BETTS, L. V. D. The Parintintin world view. Notes on Translation 41. Dallas: ILV, 1971. p. 16-21.

BIRD, S.; SIMONS, G. Seven Dimensions of Portability for Language Documentation and Description. Language, v. $79, \quad$ n. 3 , p. 557-582, 2003. Disponível em: http://www.languagearchives.org/documents/portability.pdf.

BORELLA, C. C. A nasalização em Tenharim. In: Caderno de Resumos do XLVII Seminário do Grupo de Estudos Lingüísticos do Estado de São Paulo (GEL). Bauru/SP: 1999. 
BORELLA, C. C. Análise dos sons [n] [d], [nd] e [t] na língua Tenharim. In: Caderno de Resumos do XLV Seminário do Grupo de Estudos Linguísticos do Estado de São Paulo (GEL). Campinas/SP: 1997.

BORELLA, C. C. Análise fonêmica dos sons [n]. [g], [ng] e [k] na língua Tenharim. In: Caderno de Resumos do XLVI Seminário do Grupo de Estudos Lingüísticos do Estado de São Paulo (GEL). São José do Rio Preto/SP: 1998.

BORELLA, C. C. Análise fonêmica dos sons [p], [b], [mb], [m] na língua Tenharim. In: Caderno de Resumos do XLIV Seminário do Grupo de Estudos Linguísticos do Estado de São Paulo (GEL). Taubaté/SP: 1996.

DIXON, R. M. W. The Rise and Fall of Languages. Cambridge: Cambridge University Press, 1998.

DRYER, M. Descriptive Theories, Explanatory Theories, and Basic Linguistic Theory. In: AMEKA, F.; DENCH, A; EVANS, N. (Eds.). Catching language: Issues in Grammar Writing. Berlin: Mouton de Gruyter, 2006. p. 207-234. Disponível em: https://www.acsu.buffalo.edu/ dryer/desc.expl.theories.pdf.

GALUCIO, A. V.; MOORE, D.; VOORT, H. van der. O patrimônio linguístico do Brasil: novas perspectivas e abordagens no planejamento e gestão de uma política da diversidade linguística. Revista do Patrimônio Histórico e Artístico Nacional, v. 38, p. 194-219, 2018. Disponível em: http://portal.iphan.gov.br/ uploads/publicacao/revista_patrimonio38.pdf.

HALE, K. Endangered languages: on endangered languages and the safeguarding of diversity. Language, v. 68, n. 1, mar. 1992. p. 1-42.

HIMMELMANN, N. Documentary and descriptive linguistics, Linguistics, v. 36, n. 1, p. 161-195, 1998. Disponível em: https://www.degruyter.com/downloadpdf/j/ling.1998.36.issue-1/ling.1998.36.1.161/ ling.1998.36.1.161.pdf.

MARÇOLI, O. Estudo comparativo dos dialetos da língua Kawahib (Tupi-Guarani): Tenharim, Jiahui e Amondawa. Dissertação (Mestrado em Linguística) -Universidade Estadual de Campinas (UNICAMP). Campinas, 2018.

MEIRA, S.; DRUDE, S. Sobre a origem histórica dos 'prefixos relacionais' das línguas Tupi-Guarani. Cadernos de Etnolinguística, v. 5, p. 1-30, 2013.

MICHAEL, L.; CHOUSOU-POLYDOUN, N.; O'HAGAN, Z.; BARTOLOMEI, K., DONNELLY, E. A bayesian phylogenetic classification of Tupí-Guaraní. Liames, Campinas/SP, n. 15, v. 2, jul./dez. 2015. p. 193-221. Disponível em:file://C:/Users/Pessoal/Downloads/8642301-13827-1-PB.pdf.

MOORE, D.; GALUCIO, A. V.; GABAS JUNIOR, N. O Desafio dedocumentar e preserver as línguas Amazônicas. Scientific American (Brasil) Amazônia (A Floresta e o Futuro), n. 3, p. 36-43, set. 2008. Disponível em: http://saturno.museu-goeldi.br/lingmpeg/portal/downloads/publicacoes/desafio-dedocumentar-e-preservar-moore- galucio-gabas.pdf.

NETTLE, D.; ROMAINE, S. Vanishing voices: The Extinction of the World's Languages. Oxford: Oxford University Press, 2000.

NETTO, W. F.; MORAES, J. M. Descrição fonológica preliminar da língua dos Uru Eu Wau Wau: subgrupo Mondáwa. Anais do GEL, 1993. 15 p.

PEASE, H. Parintintin grammar. Porto Velho/RO: SIL, 2007 [1968]. 78 pp. 
PEASE, H. Repetições em Tenharim (Parintintín) narrativa. Arquivos de anatomia e antropologia, vol. IVV, p. 245-261, 1979/80.

PEASE, H.; BETTS, L. V. D. Parintintin phonology. In: BENDOR-SAMUEL, David (ed.). Tupi Studies I. Glendale: Church Press Inc., 1971. p. 1-14.

PEASE, H.; BETTS, L. V. D. Anotações sobre a língua uru-eu-wau-wau. Arquivo Linguístico. Brasília: SIL, 1991. 55p.

REPÚBLICA FEDERATIVA DO BRASIL. Decreto n 7.387 de 9 dez. 2010. Institui o Inventário Nacional de Diversidade Linguística e dá outras providências. Disponível em: http://www.planalto. gov.br/ccivil_03/_Ato2007-2010/2010/Decreto/D7387.html.

RODRIGUES, A. D.; CABRAL, A. S. A. C. Revendo a classificação interna da família Tupí-Guaraní. In RODRIGUES, A. D.; CABRAL, A. S. A. C. Línguas Indígenas Brasileiras: fonologia, gramática e história. Atas do I Encontro Internacional do Grupo de Trabalho sobre Línguas Indígenas da ANPOLL. Tomo I. Editora Universitária UFPA: Belém, 2002. p. 327-337.

SAMPAIO, W. B. A. Estudo comparativo sincrônico entre o Parintintin (Tenharim) e o Uru-Eu-Uau-Uau (Amondava): contribuições para uma revisão na classificação das línguas Tupi-Kawahiva. Dissertação. (Mestrado em Linguística) - Universidade Estadual de Campinas. Campinas, 1997.

SAMPAIO, W. B. A. As línguas Tupi-Kawahib: um estudo sistemático filogenético. Tese (Doutorado em Linguística) - Universidade Federal de Rondônia (UNIR). Porto Velho, 2001.

SAMPAIO, W.; DA SILVA, V.; MIOTELLO, V. Mitos Amondawa. Porto Velho: Edufro, 2004. 50p.

SAMPAIO, W.; SINHA, C.; DA SILVA, V. Estudo descritivo/analítico dos eventos de movimento na língua uru-eu-wau-wau, dialeto Amondawa. Centre for Linguistic Research of Amazonia, Lingua Viva, v. 2, p. 513, 2004.

SAMPAIO, W.; SINHA, C.; DA SILVA, V. Mixing and Mapping: Motion, Path and Manner in Amondawa. In GUO, J.; LIEVEN, E.; BUDWIG, N.; ERVIN-TRIPP, S.; NAKAMURA, K. (Orgs). Crosslinguistic approaches to the study of language. Research in the tradition of Dan Isaac Slobin. Londres e Nova lorque: Psychology Press, 2009. p. 427-439.

SEKI, L. Gramática do Kamayurá: Língua Tupi-Guarani do Alto Xingu. Campinas: Editora UNICAMP, 2000. SINHA, C.; DA SILVA, V.; ZINKEN, J.; SAMPAIO, W. B. A. When time is not space: the social and linguistic construction of time intervals and temporal event relations in an Amazonian Culture. Language and Cognition, v. 3, n. 1, p. 137-169, 2011. Disponível em: https://www.cambridge.org/core/services/aopcambridge-core/content/view/3870C2682F9AFCEAOF453F74813CF0AA/S1866980800001058a.pdf/ when_time_is_not_space_the_social_and_linguistic_construction_of_time_intervals_and_temporal_e vent_relations_in_an_amazonian_culture.pdf. 